\title{
IgNACIO ELLACURÍA Y LA filosofíA de ORTEGA Y GASSET
}

\section{IGNACIO ELLACURÍA AND ORTEGA Y GASSET'S PHILOSOPHY}

\author{
Alfonso García Madalena \\ UNED \\ algamali11@hotmail.com
}

\begin{abstract}
Porque Ortega no es un puro hecho para nosotros, los que hablamos castellano y vivimos en una peculiar circunstancia histórica de nuestro hoy y nuestra cultura, sino que es un acontecimiento, un suceso, esto es, algo que nos ha sucedido, que nos ha acontecido culturalmente ${ }^{1}$
\end{abstract}

\begin{abstract}
Resumen: En la década de los 50 y 60 del siglo XX Ignacio Ellacuría publicó varios artículos en relación con la figura y filosofía de Ortega. Parte de estos estudios permanecieron inéditos hasta su publicación en las obras completas en el año 1996. El presente estudio lo he dividido en tres bloques temáticos: en primer lugar, los artículos escritos por Ellacuría tras la muerte de Ortega, donde glosa su personalidad y filosofía; en segundo lugar, sus reflexiones sobre la polémica que suscitó el libro de Santiago M. Ramírez y; por último, el estudio que realizó sobre el libro Meditación de la técnica, dicho ensayo por profundidad y extensión podemos considerarlo como uno de los pioneros en el estudio de la filosofía de la técnica de Ortega y Gasset.
\end{abstract}

Palabras clave: Ortega y Gasset, vida humana, neotomismo, técnica, Ignacio Ellacuría, raciovitalismo.

\begin{abstract}
In the decade of the 50 and 60 of the twentieth century, Ignacio Ellacuría published several articles in relation to the figure and philosophy of Ortega. Part of these studies remained unpublished until its publication in the complete works in the year 1.996. I have divided the present study into three thematic blocks: first, the articles written by Ellacuría after Ortega's death, where he glosses his personality and philosophy; secondly, his reflections on the controversy raised by the book by Santiago M. Ramírez and; finally, the study carried out on the book Meditation on the Technique, the above mentioned essay, for depth and extension, we can consider it to be one of the pioneers in the study of the philosophy of the technique of Ortega y Gasset.
\end{abstract}

Keywords: Ortega y Gasset, human Life, neotomism, technique, Ignacio Ellacuría, raciovitalism.

${ }^{1}$ Ignacio Ellacuría, (1996), "Ortega y Gasset, hombre de nuestro ayer", en Escritos filosóficos I. San Salvador: UCA Editores, 1996, p. 16. 


\section{INTRODUCCIÓN}

En la década de los cincuenta y primeros años de los sesenta Ignacio Ellacuría dedicó diferentes estudios a glosar la personalidad y la filosofía de Ortega y Gasset. Después de la muerte de Ortega acaecida el 18 de octubre de 1955, Ellacuría, que residía en San Salvador, es solicitado por la revista Estudios Centroamericanos (ECA) para que escriba sobre la figura de Ortega y Gasset. Esto queda constatado en una carta fechada el 11 de febrero de 1956 de Ignacio Ellacuría al Padre Ángel Martínez ${ }^{2}$, donde le comenta que estaba trabajando en un estudio de la obra de Ortega y Gasset para escribir un artículo para la revista ECA:

Me pidió el P. Garrido un artículo para ECA y, aunque ya tenía algún conocimiento de Ortega, pues había leído bastantes de sus obras principales, me decidí a meterme de bruces en él, intentando ponerme un poco en claro sobre un caso tan discutido. La disparidad de juicios entre sus críticos y sus amigos, la eficacia de su obra en tantos hombres en España y de América, me tentaba a investigar la realidad de su obra y la explicación de ese resultado tan dispar que su obra ha producido ${ }^{3}$.

Finalmente, este primer estudio se convirtió en tres artículos para la revista ECA. "Ortega y Gasset: hombre de nuestro ayer" (mayo 1956), "Ortega y Gasset, desde dentro" (junio 1956) y, "¿Quién es Ortega y Gasset?" (noviembre 1956).

Posteriormente, en el año 1958 se produjeron una serie de acontecimientos que le llevaron a escribir un nuevo artículo que quedó inédito. El dominico Santiago Ramírez es requerido por sus superiores para escribir sobre la filosofía de Ortega y Gasset. El resultado es el libro La filosofía de Ortega y Gasset ${ }^{4}$ en el que Ramírez lleva a cabo un ataque frontal al pensamiento de Ortega, intentando con todo tipo de argumentos y argucias desacreditar la filosofía de Ortega y Gasset. La polémica no se hizo esperar, Julián Marías le contestó públicamente, así como también José Luis Aranguren, Pedro Laín Entralgo y J. María Maravall. Hubo réplica de Ramírez y contrarréplicas. Además, los partidarios a favor de Ramírez

\footnotetext{
2 Ángel Martínez Baigorri (1899-1971), nacido en Lodosa (Navarra), que era jesuita, tuvo en aquellos años gran influencia intelectual sobre Ellacuría; había leído a Ortega, por lo que se desprende de la correspondencia mantenida entre ambos. También destacó como poeta.

${ }^{3}$ Ignacio Ellacuría, "Correspondencia con Ángel Martínez", en Escritos filosóficos I, San Salvador: UCA Editores, 1996, p. 212.

${ }^{4}$ Santiago Ramírez, La filosofía de Ortega y Gasset. Barcelona: Herder, 1958.
} 
también se movilizaron. Aunque Ellacuría en esos momentos residía en San Salvador, le habían llegado los ecos de la polémica. Escribe un artículo donde reflexiona sobre el libro de S. Ramírez. La crítica que hace al dominico Ramírez es correcta en las formas y durísima en el fondo. Ellacuría expresa al comienzo del artículo que pensaba que la polémica sobre Ortega se había disipado pero la publicación del libro de Ramírez hace que las posiciones a favor y en contra se radicalicen. Considera que ni Ramírez era la persona idónea para escribir sobre Ortega porque ambos pertenecían a mundos espirituales antagónicos; sus mundos vitales eran, en efecto, contrapuestos; ni los argumentos que esgrime Ramírez eran convincentes; una de las causas era la compresión errónea de la filosofía de Ortega y Gasset. Ellacuría cree que en la crítica de Ramírez hay un desenfoque fundamental, de raíz. Como consecuencia de todo ello se producen una desfiguración, tergiversación e interpretaciones erróneas de conceptos capitales en Ortega. Obviamente este artículo no lo publicó Ellacuría, ya que las ideas de Ramírez reflejaban la posición oficial de la iglesia; pero de las opiniones de Ellacuría podemos inferir que dentro de la Iglesia las posiciones no eran tan monolíticas como se transmite habitualmente, sino que existían diferentes sensibilidades y enfoques en relación con la cuestión Ortega y Gasset.

Por último, entre marzo y mayo de 1961, en Innsbruck, la ciudad austriaca donde realizó sus estudios teológicos, según consta en el manuscrito mecanografiado que se ha conservado, Ellacuría escribió un estudio sobre Meditación de la técnica de más de cien páginas. El manuscrito original, que Ellacuría tituló Técnica y vida humana en Ortega y Gasset: estudio de "Meditación de la técnica", lamentablemente quedó inédito hasta su publicación en el año 1996, en que se incluyó en sus Obras completas.

Los estudios que Ellacuría realizó en relación con la filosofía de Ortega y Gasset los he dividido en tres bloques temáticos: en primer lugar, los artículos escritos por Ellacuría a la muerte de Ortega para la revista $E C A$, en el año 1956, donde analiza la significación de Ortega, su persona y obra; el segundo bloque temático, por una parte, estaría en relación con la búsqueda por parte de Ellacuría de una filosofía integradora, de conciliación entre la filosofía tomista y la filosofía raciovitalista de Ortega y Gasset y, por otra parte, en la crítica al libro La filosofía de Ortega y Gasset (1958) del dominico Santiago María Ramírez; el último bloque 
temático lo sitúo en 1961, época en que Ellacuría escribió un estudio muy profundo y extenso de la filosofía de la técnica de Ortega tomando como base de este estudio el libro Meditación de la técnica.

\section{ElLACURÍA ANTE LA MUERTE DE ORTEGA.}

En mayo de 1956, se publicó en el número 104 de la revista Estudios Centroamericanos ( $E C A)$ el primero de los tres artículos que Ellacuría dedicará a Ortega después de su muerte acaecida el 18 de octubre de 1955, "Ortega y Gasset: hombre de nuestro tiempo". En estos tres artículos estudia la figura y la persona de Ortega. Ellacuría comienza su primer ensayo analizando los cuatro tipos de respuesta que se han producido tras la muerte de Ortega. En primer lugar, sería "una conjura del silencio"5 respecto de su obra y su persona. Esta posición la considera ingenua y utópica dada la trascendencia de Ortega como personaje público y pensador; en segundo y tercer lugar, tenemos las posiciones extremas $y$ en muchas ocasiones injustas en las que se incide de manera tendenciosa en ciertos aspectos del pensamiento orteguiano soslayando otros de manera intencionada; por una parte, "la del látigo y el incensario"6, al subrayar todos los aspectos negativos obviando su cualidades positivas y, por otra parte, la posición en que sólo se resaltan los aspectos notables y positivos del pensamiento orteguiano; por último, estarían los que buscan una revisión serena de la labor de Ortega.

Ellacuría realiza una valoración de Ortega individualmente considerado, pero piensa que lo más relevante y significativo de la figura de Ortega es como prototipo de hombre moderno. Veamos la consideración que hace de Ortega:

Individualmente considerado, ofrece por las proyecciones de su personalidad, por el talante y las pretensiones que representa, por el proceso implicado de su vida, un interés indiscutible. Sobre ello se halla el significado de su obra: la transformación del ambiente cultural español y, en medida decreciente, el americano y el europeo; la preocupación viva, personal y constante de los problemas de actualidad más honda y punzante [...]: el empeño de renovación y humanización, el esfuerzo por conjugar

\footnotetext{
${ }^{5}$ Ignacio Ellacuría, "Ortega y Gasset, hombre de nuestro ayer", en Escritos filosóficos I. San Salvador: UCA Editores, 1996, p. 15.

${ }^{6}$ Ibíd., p.16.
} 
las exigencias más extremas de la razón y la vida; la espléndida vivencia de los problemas que toca y la no menos espléndida re-vivencia de esos problemas ${ }^{7}$.

Ellacuría en su reflexión sobre la figura de Ortega considera que aunque todas estas valoraciones sobre su personalidad e incidencia sobre la cultura española son de suma importancia, todavía hay algo más significativo cuando estudiamos "lo más típico del caso orteguiano."8

Lo que en él encontramos de más significativo es su modernidad, el ser representación acabada y significativa del intelectual de hoy, con sus oscuridades y pretensiones de luz, aciertos y errores, al llevar consigo y haber comunicado muchas realidades que los hombres actuales llevamos dentro, a veces sin saberlo, a veces sin poderlas expresar.

Lo reconocen amigos y adversarios. "Prototipo del hombre europeo de cultura", escribe Derisi. [...].

Decir de Ortega que es prototipo del hombre moderno no quiere significar una atribución de paradigma o de modelo. Es tan sólo reconocer un hecho, todo lo lamentable que se quiera, pero cierto: el hecho de que Ortega representa, por la índole de sus preocupaciones e intereses, por el estilo de su pensamiento y estimaciones, por el carácter de sus soluciones al mundo presente, al hombre de hoy ${ }^{9}$.

Ellacuría quiere resaltar con la aseveración que Ortega es "prototipo de hombre moderno", que Ortega representa a la figura del intelectual de su tiempo. No únicamente que haya tratado de cosas modernas sino que es el prototipo del hombre moderno. Esto es, no quiere con ello decir Ellacuría que Ortega sea un modelo o ejemplo perfecto sino que, por el talante de su pensamiento, "con sus errores y pretensiones de luz, aciertos y errores"10, Ortega es parte de nuestro mundo cultural, porque ha transmitido ideas, reflexiones, realidades "que los hombres actuales llevamos dentro, a veces sin saberlo, a veces sin poderlas ex-

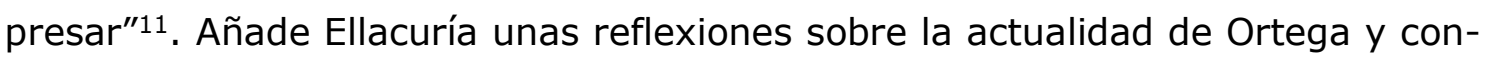
sidera que aunque sea un hombre de ayer ${ }^{12}$, considera que su pensamiento opera sobre el presente y lo seguirá haciendo en el futuro porque:

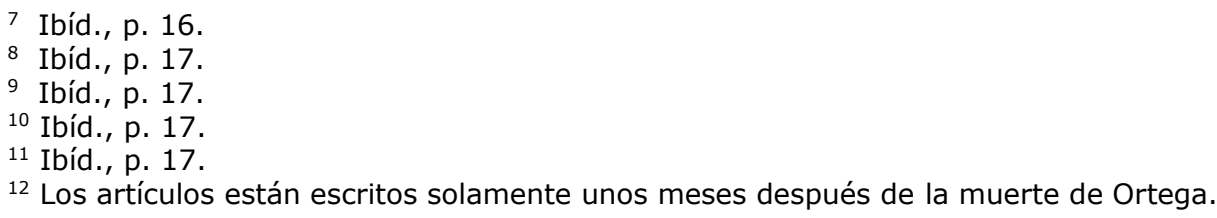


Ha configurado los horizontes y los dinamismos intelectuales de algunos de los pensadores que hoy mandan en el mundo cultural de habla española y en cuanto ha formado un ambiente, unos medios de trabajo, unas preocupaciones y unos intereses, unas posibilidades humanas, en fin, que condicionan mediata o inmediatamente el presente que vivimos y el futuro que nos sobrevive ${ }^{13}$.

Ellacuría cita a Marañón: "ahora vivimos, poco o mucho, en nuestro repertorio intelectual de Ortega [...]"14. En 1941 Joaquín Iriarte había escrito que Ortega había gobernado desde su cátedra de metafísica "haciendo efectivamente que un pueblo fuese lo que su metafísico quiso que fuese"15. Cita también Ellacuría a José Gáos, quien que asegura que fue "la representación suprema, en el aspecto intelectual de un periodo de la cultura española, y aun de la cultura de los demás países de lengua española"16.

Ante los escritos de Ortega considera Ellacuría que no se trata de asumir todo lo planteado por Ortega de forma acrítica ni tampoco de rechazar todo su pensamiento. Desde su punto vista, trata de asumirlo, de comprenderlo, apreciando sus valores positivos y por otra parte, ponderar sus "deficiencias radicadas en la proclividad de sus escritos hacia un relativismo filosófico y hacia un humanismo laico, descristianizado y antropocentrista"17.

No es maestro perfecto por su misma contextura psicológica, como por la circunstancia cultural que le tocó vivir, que coartaron muchas de las dimensiones que un pensador y un filósofo deben poseer en cuanto a dedicación, concentración y profundidad, rigor y sistema. No lo es, en fin, porque su cerrazón a los horizontes religiosos le escamoteó muchas soluciones, decisivas soluciones, más aún, muchos y decisivos datos del problema humano tanto individual como social e histórico, aun beneficiándose en su educación y en enfoques posteriores de los valores culturales del cristianismo ${ }^{18}$.

El segundo artículo publicado en el año 1956 es "Ortega y Gasset, desde dentro". Ellacuría considera que para hacer una evaluación correcta y entender el pensamiento orteguiano debemos estudiarlo desde dentro, introduciéndonos

\footnotetext{
${ }^{13}$ Ignacio Ellacuría, "Ortega y Gasset, hombre de nuestro ayer", ob. cit., p. 18.

${ }^{14}$ Gregorio MARAÑón, "Universidad y retórica en Ortega", ABC, 20 de octubre de 1955.

15 Joaquín Iriarte, Ortega y Gasset. Su persona y su doctrina. Madrid: Razón y Fe, 1942, p. 5.

${ }^{16}$ Ignacio Ellacuría, "Ortega y Gasset, hombre de nuestro ayer", ob. cit., p. 19.

17 Ibíd., p. 22.

18 Ibíd., p. 22.
} 
en su vida y en su obra. El título de artículo rememora al publicado por Ortega en 1932, Pidiendo un Goethe desde dentro ${ }^{19}$.

En el caso particular de Ortega su obra está tan imbricada en su trayectoria vital que "en raras ocasiones nos tocará enfrentarnos con un mutuo influjo tan notable entre un pensamiento filosófico y una vida" 20 y continúa diciendo que su pensamiento "no es sino el constante bracear por descubrir el logos vital de su existencia y un esforzarse por lograr revivir en su sentido penetrante de tan cálidas vivencias"21.

Es en ese desde dentro donde a Ortega se entiende, allí donde radica el más genuino sistema orteguiano, el de la continuidad íntima de su actitud ante las cosas, siempre una, a pesar de todas las fluctuaciones y de las modas pasajeras que, por su sensibilísima condición padecía22.

En el último artículo publicado en la revista ECA, en el año 1956, "¿Quién es Ortega y Gasset?". Ellacuría hace una interpretación de la vida de Ortega desde su obra. En esta interpretación sintética que realiza distingue cuatro rasgos que según él caracterizan la personalidad de Ortega.

En primer lugar, estudia el binomio vida-cultura. Parte de que en el vivir y pensar existe una preocupación radical: la de la vida y la cultura y, los problemas que la unión de ambas conlleva. La vida es el dato radical y fundamental. Y uno de los rasgos más característicos de Ortega es su búsqueda de plenitud vital23, es un rasgo "en el que veía como la sangre vivificante de toda cultura y el impulso de todo movimiento poderoso y fecundo"24.

Toda su vida fue una permanente navegación, dice Ellacuría, detrás del instante huidizo, circunstancial, mudable "prefiriendo lo perfectible a lo inmutable, la trémula mudanza del tiempo al reposo y el silencio de eternidad"25. La vida de Ortega, de acuerdo a uno de los rasgos que se desprende de su obra, es "Una

\footnotetext{
19 José Ortega y Gasset, V, 120-142.

20 Ignacio Ellacuría, "Ortega y Gasset, desde dentro", en Escritos filosóficos I, San Salvador: UCA Editores, 1996, p. 27.

${ }^{21}$ Ibíd., p. 27.

22 Ibíd., p. 31.

23 "Plenitud vital", "vitalidad ascendente", "tonalidad vital", etc. son expresiones muy utilizadas en los años 20 hasta La rebelión de las masas; posteriormente, con el comienzo de lo que denominó "la segunda navegación" donde reelaboró y fijo su filosofía ciertos términos dejó de utilizarlos, entro ellos están los anteriormente citados.

${ }^{24}$ Ignacio Ellacuría, "¿Quién es Ortega y Gasset?, en Escritos filosóficos I. San Salvador: UCA Editores, 1996 , p. 36.

${ }^{25}$ Ibíd., p. 36.
} 
existencia que necesitaba vivirlo todo y vivirlo en plenitud", esto le llevó al rechazo de los especialismos angostos. "Antes que ser profesional o investigador, quiso ser hombre. Ortega, profesión: hombre"26.

En su vida personal junto de manera extraordinaria la vida y la cultura. Fue algo que partía de sus mismas entrañas, algo que necesitaba urgentemente, algo de lo que hizo misión propia, tema de nuestro tiempo. Pocas vidas tan cultas como la de él y pocas culturas tan vitales como la suya. Esto y la gran fuerza y tensión con que mantenía los dos extremos de vida y cultura, creo son la razón fundamental del notorio arrastre que ejerció su persona ${ }^{27}$.

En segundo lugar, en su interpretación de la personalidad de Ortega desde su propia obra, destaca Ellacuría la "pretensión de actualidad". Ese vivir el aquí y ahora que tantas veces menciona Ortega en sus escritos. La obligación que sentía de vivir el presente, la existencia concreta del momento, "lo forzaba a una cultura del presente"28. Todo ello le llevó a pretender ser siempre actual, en permanente renovación, conocedor de todos los temas de su tiempo: "Le preocupaba abandonar el pulso del momento $y$, por ello, se pliega a todos los vaivenes y novedades, temeroso de perder actualidad, dejando de ser adelantado mayor de movimientos culturales"29.

Pero Ellacuría apunta que la actualidad toma en Ortega la forma de circunstancialidad, "que es forma de vida antes que de su pensamiento"30. Esta circunstancialidad le llevó a escribir sobre los temas más próximos que el presente le demandaba:

No escribía sino de los temas que el momento reclamaba y en la extensión exacta con que lograban mantener su fuego vital dentro y fuera de sí. Más que acomodar la vida al pensamiento, tratando de vivir lo que pensaba, acomodaba el pensamiento a la vida, tratando de pensar lo que vivía ${ }^{31}$.

\footnotetext{
${ }^{26}$ Ibíd., p. 38.

27 Ibíd., p. 38.

28 Ibíd., p. 39.

${ }^{29}$ Ibíd., p. 39.

${ }^{30}$ Ibíd., p. 39.

${ }^{31}$ Ibíd., p. 40.
} 
En tercer lugar, Ellacuría expone la forma particular de mirar estos temas circunstanciales por parte de Ortega, su dimensión como intelectual y filósofo. Quería ser espectador de la vida que lo circundaba:

Mas como en su estimación no se daba sino un pensamiento auténtico, el filosófico, pretendió decididamente ser filósofo. En ello veía la forma más perfecta de vida: "la filosofía que es la vida auténtica, la vida poseyéndose a sí misma". Ortega llevaba a todas las cuestiones, aun a las más superficiales, un espíritu y una formación de filósofo y ello le permitía avistar desde cualquier claraboya inaudita la gestación psicológica esencial de la vida como existencia humana. Llevaba también un afán de meditación personal no improvisada ${ }^{32}$.

En cuarto y último lugar, Ellacuría arguye que de los escritos orteguianos y de su estilo se desprende una tendencia hacia el narcisismo33; "la especial condición de su estilo, acicalado, detallista, extremado en el escorzo, lo significan suficientemente" 34 . Otra faceta que destaca de Ortega es la autosuficiencia: "un hombre contento de sí mismo, aunque con el suficiente descontento que le sirviese para la propia superación" y, esta satisfacción personal de sí mismo va unida al gusto por exhibirse, "siente - dice del hombre en general-que si lo que él es no lo es a la vista de los demás, valdría tanto como si no lo fuera"35, Y, finalmente un cierto egocentrismo, "presencia de un yo que necesita imponerse, abrirse camino y ser reconocido" 36 .

\section{REFLEXIONES SOBRE LA POLÉMICA POR LA CRÍTICA DEL DOMINICO P. RAMÍREZ}

Desde la muerte de Ortega en octubre de 1955 Ellacuría dice que "parecía dormida la polémica frente a Ortega"37, pero la publicación del libro La filosofía de Ortega y Gasset del dominico Santiago María Ramírez ${ }^{38}$ reavivó de nuevo la polémica en torno a la figura de Ortega y Gasset.

\footnotetext{
32 Ibíd., p. 42.

33 Menciona que dos veces Carlos París hace referencia a este narcisismo orteguiano en el artículo "Meditación sobre la filosofía de Ortega" publicado en la revista Arbor (1956).

${ }^{34}$ Ignacio Ellacuría, "¿Quién es Ortega y Gasset?, ob. cit., p. 43.

35 J. Ortega y Gasset, "Divagación ante el retrato de la Marquesa de Santillana": II, pp. 778.

${ }^{36}$ Ignacio Ellacuría, "¿Quién es Ortega y Gasset?, ob. cit., p. 43.

37 Ignacio Ellacuría, "Posibilidad y modo de aproximación entre la filosofía escolástica y la filosofía moderna (Reflexiones ante el libro de Ramírez: La filosofía de Ortega y Gasset), en Escritos filosóficos I. San Salvador: UCA Editores, 1996, pp. 223.

${ }^{38}$ Santiago M. Ramírez (1891-1967) fue una de las figuras más representativas del neotomismo español del siglo XX. Perteneció a la Orden de los predicadores, también conocida como los dominicos. Por
} 
Vamos a tratar tres puntos en los que Ellacuría incide principalmente: en primer lugar, comienza por exponer los aspectos que podríamos considerar positivos del libro de Santiago Ramírez; en segundo lugar, la inadecuada actitud de Ramírez para evaluar la filosofía de Ortega; en tercer lugar, la tergiversación de la filosofía de Ortega que se da en esa crítica; y, por último, nos referiremos a un intento de Ellacuría de conciliar y buscar puntos de encuentro entre la filosofía tomista y la filosofía vitalista moderna.

Ellacuría, primero, expone y evalúa al comienzo de este ensayo los aspectos positivos de la obra de Ramírez: en primer lugar, reconoce que es un libro muy superior a lo escrito hasta ese momento sobre Ortega, sea por partidarios o por detractores. Reúne Ramírez gran cantidad de textos de Ortega presentándolos de una manera ordenada y sistemática; en segundo lugar, nos descubre al dominico Ramírez como un gran polemista y gran conocedor de la filosofía escolástica; en tercer lugar, el momento álgido de su crítica a Ortega es la refutación según él de aquellas erróneas interpretaciones que Ortega hace del aristotelismo tomista39; y, en cuarto lugar, considera que la refutación de Ramírez desde el punto de vista del catolicismo y la filosofía perenne tienen un valor indiscutible.

Segundo, Ellacuría considera que las refutaciones que hace Ramírez de Ortega no están exentas de carencias y defectos. Primeramente, analiza si la actitud de Ramírez es la idónea para hacer una crítica de la filosofía raciovitalista de Ortega, pues, aunque Ellacuría le concede ser un gran dialéctico y polemista,

requerimiento de sus superiores se le solicitó escribir un libro donde se rebatiera la filosofía de Ortega y Gasset. La aparición de su libro La filosofía de Ortega y Gasset recibió la crítica de algunos orteguianos como hemos mencionado anteriormente. Este hecho le llevo a escribir dos libros más, ¿Un orteguismo católico? (1958) y La zona de seguridad (1959). Pero en aquellos años 50 se escribieron gran cantidad de artículos a favor y en contra del libro. Veamos para finalizar esta breve aproximación a S. Ramírez cómo glosaban su figura aquellas personas más próximas a su pensamiento, por ejemplo, Guillermo Fraile, en el año 1959 resaltaba la figura y el pensamiento de Ramírez en su artículo "El P. Ramírez escribe sobre Ortega" en relación al libro sobre Ortega: "Pero tampoco es prudente precipitarse a lanzar prematuros veredictos de incapacidad, cuando se trata de un escolástico determinado; que trabaja en una celda circundado por todas partes menos por una de los libros de una riquísima biblioteca particular, que tiene una mente alerta, vigilante y siempre abierta durante muchos años a los vaivenes del pensamiento europeo, y que, si actualmente reside en Salamanca, cuna de la segunda escolástica, antes rodó largos años por Italia, Suiza, Francia, Bélgica, Alemania, Estados Unidos, y que, manteniéndose firme en una sólida posición ideológica, es un espíritu amplio y acogedor, que constituye la más perfecta antítesis de la cerrazón mental que, por definición, se suele atribuir a los escolásticos" (p. 234). O en referencia a la dureza de las críticas de Ramírez, expone: "Hay que reconocer que la crítica del P. Ramírez es dura, si bien para pronunciar su fallo no lo hace desde su punto de vista particular, sino siempre contrastando las afirmaciones de Ortega con las enseñanzas de Santo Tomás y de la Iglesia católica. Pero dureza no arguye falta de objetividad, si las proposiciones en litigio merecen efectivamente los calificativos que se les aplican" (pp. 237-238).

${ }^{39}$ Dentro del sistema filosófico orteguiano la filosofía escolástica tiene una incidencia mínima por no decir nula y, en la mayoría de las ocasiones, Ortega la menciona para descalificarla. 
cree que "patentiza graves limitaciones" 40 para ser la persona adecuada para hacer un análisis crítico de la filosofía orteguiana:

Al referirse a la vida como realidad radical [...]: su actitud es absolutamente dialéctica y polemista, tratando de reducir a absurdos al adversario, pero sin esforzarse en analizar la cosa en sí; es, consecuentemente, una actitud negativa en que ni se intenta comprender interiormente la posición del adversario en lo que pueda tener de aprovechable y superable; negativismo exagerado y miope al enfocar todo, o casi todo, por la lente de lo contradictorio donde no hay sino oposiciones conciliables en el ser complejo de la vida humana; actitud discutible además en su mismo plan dialéctico precisamente por no atender a posibles y legítimas escapatorias de la contradicción pretendida; repudiable, por no situarse en el punto de vista adversario, que no es el escolástico de unum per se entre mundo y yo ni el de la refutación puramente dialéctica del idealismo, sino el de la presentación de un realidad intuida que sólo después de intuida puede ser presentada como base dialéctica $[\ldots]^{41}$.

En cuanto al procedimiento utilizado por Ramírez es siempre el mismo, dice Ellacuría; se basa en traer el pensamiento ajeno al propio y apreciar su conformidad y disconformidad a través de sus categorías: "Ramírez trae la doctrina orteguiana al tribunal de la escolástica no solo con la pretensión de que ésta goza de la posesión de la verdad"42, pero, además, con el pensamiento propio enfoca las realidades estudiadas por Ortega. Habiéndose percatado Ramírez de que Ortega no demuestra por silogismos sus proposiciones utiliza este método para juzgar a Ortega y buscar contradicciones en la filosofía orteguiana, cuando la pretensión de Ortega es llevarnos a la realidad misma. Veamos un caso concreto, la "idea de hombre", donde Ramírez busca contradicciones en las afirmaciones orteguianas que Ellacuría utiliza para ejemplificar este modo de proceder:

Pero es que, además, la idea del hombre, tal como la concibe y expone Ortega, es incoherente y contradictoria en sí misma. Según nuestro filósofo, el hombre no es su cuerpo ni su alma ni el compuesto de alma y cuerpo, sino su vida [...] más en otra parte asegura que el alma y el cuerpo son una parte de la circunstancia [...] y que esa circunstancia es la mitad del hombre o de la vida [...] según esto, el cuerpo y el alma son por lo menos uno de los elementos radicales de que se compone la vida

\footnotetext{
${ }^{40}$ Ignacio Ellacuría, "Posibilidad y modo de aproximación entre la filosofía escolástica y la filosofía moderna (Reflexiones ante el libro de Ramírez: La filosofía de Ortega y Gasset), en Escritos filosóficos I. San Salvador: UCA Editores, 1996, pp. 228.

${ }^{41}$ Ibíd., p. 228.

42 Ibíd., p. 229.
} 
humana, la mitad de ella y del hombre. No es, pues, exacto ni coherente decir que el hombre no es su alma ni su cuerpo. ${ }^{43}$

Ellacuría argumenta en contra de Ramírez que tal contradicción no se da en la argumentación orteguiana. Con sólo añadir el adverbio "adecuadamente" la idea orteguiana de hombre adquiere plena exactitud lógica, dice Ellacuría. Para Ortega la vida humana es quehacer, la vida se nos da, pero no se nos da hecha y por eso constituye un drama, un esfuerzo, un riesgo permanente. Obviamente el cuerpo es un ingrediente esencial de mi vida, pero no es drama sino algo con lo que cuento para hacer mi vida. Por tanto, el cuerpo, al no ser drama, no es la vida ni es el hombre. "Si falta rigor de expresión, es tan hacedero el suplirlo que es plenamente desacertado e injusto argüir precisamente por ese hueco de tan obvio relleno"44. Por otra parte, otro procedimiento en el que Ramírez se nos muestra como maestro sin igual es en el de los insultos y dicterios, en la bajeza de los ataques: "No es raro en Ramírez este descenso de tono al extremar las consecuencias extrafilosóficas y argumentar desde ellas, como en las alusiones a cobrar nóminas, a filosofía de tarados y anormales, [...]. Lo cual no es decente ni es justo". ${ }^{45}$

La cerrazón mental que tal postura insinúa, la acritud y ensañamiento intelectual que refleja, la desnivelación de tono y el negativismo radical que patentiza, la falta de profunda seriedad humana y de respeto a las opiniones ajenas que exterioriza, serán armas que una vez más se esgriman contra la intolerancia y la falta de modales intelectuales de los pensadores escolásticos españoles. ${ }^{46}$

Otro punto en el que incide Ellacuría en relación con el tratamiento de la filosofía de Ortega y Gasset que hace Ramírez es la deformación que realiza del pensamiento orteguiano y la causa principal es el desenfoque central de todo su libro:

Por eso, es lícito hablar de desenfoque central en su obra. No se trata de discutir en particular si tal apreciación es exacta y la otra no lo es, sino más profundamente que

${ }^{43}$ S. Ramírez, La filosofía de Ortega y Gasset, Barcelona: Herder, 1958, pp. 212-213.

${ }^{44}$ Ignacio Ellacuría, "Posibilidad y modo de aproximación entre la filosofía escolástica y la filosofía moderna (Reflexiones ante el libro de Ramírez: La filosofía de Ortega y Gasset), ob. cit., p. 230.

45 Ibíd., p. 230.

${ }^{46}$ Ibíd., p .231. 
el punto de mira primero y fundamental es el descentrado, fenómeno al que se debe la deformación con que se presentan al lector las verdaderas imágenes orteguianas ${ }^{47}$.

Ellacuría analiza cómo este desenfoque central, fundamental, de raíz lleva a la desfiguración, tergiversación e interpretaciones erróneas de conceptos capitales en Ortega como "vida humana"48, "yo", "idea de hombre" o las incorreciones que comete cuando analiza la conocida frase "yo soy yo y mi circunstancia".

En último lugar, Ellacuría después de haber expuesto las impresiones que le han sugerido las críticas de Ramírez a la filosofía de Ortega, de la que tenía un amplio conocimiento por los estudios que había realizado de esa obra en años anteriores, propone al final de este ensayo "la posible conciliación entre las posturas escolásticas y modernas mediante una complementación jerárquica" 49 . Busca un punto de encuentro entre la filosofía perenne y la filosofía raciovitalista, un proyecto de superación, de conciliación de las posturas encontradas de las dos corrientes. Esta conciliación "no es la de un eclecticismo sin jerarquía, la aquí propugnada es la de una ampliación de campos, de enfoques y de procedimientos a partir de la ya lograda por la filosofía perenne"50.

Que no se trate de un eclecticismo sin jerarquía significa que intenta sintetizar la filosofía escolástica y la filosofía raciovitalista orteguiana. Por una parte, considera que "el tomismo se está cerrando a una complementación vital, con lo que pierde contacto inmediato con la realidad humana tal como es"51. No se trata de volver a estudiar y revivir al Tomas de Aquino de la Edad Medía, "sino que su misión específica es traerlo a la altura del propio tiempo, revivirlo, pero con la modulación característica del propio mundo"52. En conclusión, a las filosofías modernas les falta un sólido fundamento metafísico, una gran potencia de procedimiento lógico, crítico y sistemático y, por otra parte, el tomismo está necesitado de un complemento vital:

47 Ibíd., p. 236.

48 Por ejemplo, cuando trata un concepto tan central para Ortega como la vida humana, Ellacuría dice "el mismo concepto de vida - como una realidad de muy complejas dimensiones que no puede ser entendida como una sustancia completa, integrada por dos incompletas, yo y la circunstancia- está desfigurado por haber sido pensado desde esas categorías de sustancia y unum per se. De haberlo considerado así vienen los absurdos de juzgar lo nuevo según los patrones antiguos, de traer lo ajeno a lo propio [...]" (Escritos filosóficos, p. 236).

49 Ibíd., p. 244.

${ }^{50}$ Ibíd., p. 249.

${ }^{51}$ Ibíd., p. 239.

52 Ignacio Ellacuría, "El tomismo, ¿es un humanismo? en Escritos filosóficos I. San Salvador: UCA Editores, 1996, p. 388. 
Cualquier pensador vital siente que en las fórmulas clásicas se escapa lo existente y se difumina el problema particular; esa distancia entre la naturaleza universal, unívoca para todos, y la realidad concreta bien diferenciada aun dentro de sus marcos generales, la realidad humana con su peculiar y próximo vivir, puede ser salvada hasta cierto punto por los análisis preñados de contenido vital con que los modernos logran poner en contacto a sus lectores con la vida tal como es y se vive ${ }^{53}$.

Ellacuría abandonará en los años siguientes este proyecto de conciliación de la filosofía tomista y la filosofía de Ortega y Gasset por las dificultades de su concreción. En este abandono es decisivo el encuentro con Zubiri a principios de los años sesenta y, posteriormente, esta concreción la encontró en la realidad histórica y social de Centroamérica.

\section{ESTUdIO SOBRE MEDITACIÓN DE LA TÉCNICA (1961)}

En 1961 Ellacuría escribió un estudio sobre Meditación de la técnica, libro este que recoge las lecciones impartidas por Ortega en la Universidad de verano de Santander en 1933. Ellacuría tituló su estudio Técnica y vida humana en Ortega y Gasset: Estudio de "Meditación de la técnica". Lo escribió durante los meses de marzo y mayo de 1961, en Innsbruck (Austria), pero el texto quedó inédito y no se publicó hasta el año 1996 cuando se publicaron las Obras completas de Ellacuría. El estudio sobre Meditación de la técnica lo dividió Ellacuría en tres partes. La primera trata sobre el método en Ortega; la segunda sobre la vida humana y, en tercer lugar, sobre el ser de la técnica. Para contextualizar el texto de Ortega del año 1933 en relación con la técnica debemos partir del hecho de que Ortega estaba plenamente instalado en la idea de vida humana como dato radical e idea básica y fundamental de su sistema. Había comenzado lo que él denominó "la segunda navegación", que se fundamentaba en la idea de vida humana como dato radical y primario, y desde la vida humana va a enfocar Ortega el problema de la técnica. Ellacuría considera que "quizás el hallazgo más valioso de Ortega en este ensayo sobre la técnica haya sido su radicación en la vida humana"54.

\footnotetext{
${ }^{53}$ Ignacio Ellacuría, "Posibilidad y modo de aproximación entre la filosofía escolástica y la filosofía moderna (Reflexiones ante el libro de Ramírez: La filosofía de Ortega y Gasset", ob. cit., pp. 246-247.

${ }^{54}$ Ignacio Ellacuría, "Técnica y vida humana en Ortega y Gasset. Estudio de "Meditación de la técnica", en Escritos filosóficos I. San Salvador: UCA Editores, 1996, p. 496.
} 
Para Ortega la vida individual, mi vida, es el dato radical, la realidad primaria, fundamental, donde todas las otras realidades radican. Lo primero que hay en el universo, dice Ortega, es nuestro vivir y todo lo demás, lo hay o no lo hay en nuestra vida, la vida individual de cada cual. Ortega parte en su estudio sobre la técnica analizando el concepto de "necesidad humana":

Ortega ha visto bien que el concepto de "necesidad humana" importa un elemento subjetivo, y esto no sólo por ser humana, sino por ser necesidad. La necesidad es la respuesta subjetiva a lo necesario, el echar de menos y el anhelar lo necesario. Un "necesario" que apunta a un "para" que, en definitiva, es el "querer vivir". [...] Vida humana que quiere ser ella misma en un mundo y con un mundo que le ofrece a la par posibilidades y dificultades para ser lo que es. La técnica queda enmarcada en el horizonte de inteligibilidad que le prestan el querer vivir del hombre y el ser su vida lo que efectivamente es ${ }^{55}$.

El ser humano para vivir tiene que satisfacer unas necesidades, cuando la naturaleza no le presta los medios para poder satisfacerlas, inventa un nuevo tipo de hacer que consiste en producir lo que no estaba ahí. "Sentir ciertas necesidades como especialmente gravosas, como algo requerido para vivir, pero que no es el vivir mismo, ilumina el esencial carácter de alteridad respecto del ámbito de esas necesidades, que es propio de la vida humana"56. Este nuevo tipo de hacer son los actos técnicos y el conjunto de estos actos es la técnica, reforma que el hombre impone a la naturaleza en vista a la satisfacción de sus necesidades. Ellacuría dice que su objetivo primero es que "lo necesario para la vida humana no se presente con carácter de necesidad, cuya satisfacción nos impediría la vida humana"57. La técnica es constitutiva a la vida humana porque sin la técnica no se da la vida humana. Ortega afirma taxativamente: "El hombre empieza cuando empieza la técnica"58. Pero Ellacuría se pregunta ¿Por qué es esto así?

La vida humana como realidad radical es el ámbito donde se da la coexistencia del yo y la circunstancia. El "yo" es el proyecto vital, programa de ser que oprime a la circunstancia, reobra sobre la circunstancia transformándola en

\footnotetext{
${ }^{55}$ Ibíd., p. 497

56 Ibíd., p. 498

57 Ibíd., p. 498

58 [Introducción al curso ¿Qué es la técnica?]: IX, 27.
} 
mundo. Esta transformación siempre es técnica. La reflexión orteguiana sobre la técnica, a nivel metafísico (coexistencia yo/circunstancias), le lleva a afirmar que la técnica solo puede darse en la combinación entre dos entes heterogéneos que se ven obligados a unificarse. "Un ente, el hombre, se ve obligado, si quiere existir, a estar en otro ente, el mundo o la naturaleza."

La técnica logra que el ser humano este en el mundo con cierta seguridad. No quiere esto decir que sin técnica no se pueda vivir, los animales de hecho viven sin técnica ${ }^{60}$, pero el ser humano no solamente quiere estar, sino que busca bienestar. El bienestar es algo en permanente cambio, variable en función de los deseos humanos, que están en relación con "los diferentes tipos de aspiraciones vitales que el ser humano ha tenido a lo largo de la historia. Por eso lo más necesario para el hombre es lo superfluo. Dice Ortega, "el hombre es un animal para el cual sólo lo superfluo es necesario"61, y añade: "La técnica es la producción de lo superfluo: hoy y en la época prehistórica"62. El concepto de necesidad humana abarca tanto lo necesario como lo superfluo, porque el vivir del hombre no es sólo el estar como el animal, sino el bienestar. Por esta razón, lo que es necesario para sobrevivir por parte de los animales pasa a no ser una necesidad humana, mientras que lo superfluo se permuta en la auténtica necesidad humana. Por tanto, el hombre comparte con el resto de los animales unas necesidades vitales o primarias, pero a diferencia de los demás animales estas necesidades primarias las siente como propias. Como hemos mencionado, no busca simplemente vivir sino bienestar. Mediante la técnica el hombre reduce al mínimo, y a veces elimina, el esfuerzo que le impone la naturaleza; emplea el esfuerzo ahorrado para inventarse a sí mismo, para proyectar y autofabricarse su vivir, "y precisamente a esa vida inventada, inventada como se inventa una novela o una obra de teatro, es a lo que el hombre llama vida humana, bienestar"63. Para finalizar su análisis sobre el ser de la técnica Ellacuría remite a dos hechos condicionados por el ser de la técnica pero que, al ser su manifestación concreta,

${ }^{59}$ Meditación de la técnica, V, 568

${ }^{60}$ En algunos animales como los chimpancés se ha comprobado que son capaces de manipular herramientas pero a un nivel muy rudimentario.

61 "Ensimismamiento y alteración": V, 561.

62 "Ensimismamiento y alteración", V, 562.

63 "Ensimismamiento y alteración": V, 567. 
nos sirven para su comprobación: los presupuestos psicológicos y la evolución de la técnica.

En primer lugar, argumenta que Ortega nos ha ejemplificado con alguno de los programas de ser que han existido históricamente, en la figura de vida del gentleman inglés, del bodhisatva hindú, del hidalgo español, el asceta medieval, etc., "su esencia metafísica universal en sus realizaciones concretas empíricas"64. Igualmente podemos concretizar los presupuestos psicológicos "en el hombre de ese fenómeno que llamamos técnica"65. En esencia el mundo para el hombre no es siempre fijo, rígido, pautado. No se nos da como expone Ortega como facilidades o dificultades puras, sino como un conjunto de facilidades y dificultades. Dentro de los presupuestos psicológicos Ellacuría considera que no todos sus elementos sino algunos necesitan alguna precedencia, en concreto, la inteligencia y la imaginación.

En relación con la inteligencia Ortega argumenta que "la inteligencia técnica es una capacidad, pero la técnica es el ejercicio efectivo de esa capacidad, que muy bien podría quedar en vacación"66; pero, además, entiende la inteligencia como "una función puramente mecánica, sin disciplina ni orientación, [...] no puede sacar de sí su propia orientación"67. Ante estas afirmaciones orteguianas Ellacuría establece tres premisas:

Primero (a), no es suficiente con tener capacidad para hallar nuevas relaciones entre las cosas, nuevos instrumentos, para que se produzca el fenómeno técnico. Segundo (b), "Ni siquiera una función activa $y$, no ya una mera capacidad que descubre relaciones entre las cosas y puede inventar instrumentos y métodos [...] para satisfacer las necesidades del propio sujeto"68 es capaz del fenómeno técnico. Tercero (c), para que se pueda producir el fenómeno técnico es preciso una nueva capacidad para formarse proyectos vitales, figuras de vida.

Las cuestiones que plantea Ellacuría ante estas premisas es sí en un ser que tiene la capacidad (a) y la función (b) no debería darse también (c), "y si la actuación de ambas capacidades no es necesaria"69. Según Ellacuría a ambas

${ }^{64}$ Ignacio Ellacuría, "Técnica y vida humana en Ortega y Gasset. Estudio de "Meditación de la técnica", ob. cit., p. 508.

${ }^{65}$ Ibíd., p. 508

66 "Ensimismamiento y alteración": $\vee, 586$.

67 "Ensimismamiento y alteración", V, 587.

${ }^{68}$ Ignacio Ellacuría, "Técnica y vida humana en Ortega y Gasset. Estudio de "Meditación de la técnica", ob. cit., p. 509

69 Ibíd., p. 509. 
preguntas respondería Ortega negativamente. Por una parte, basándose en los trabajos de campo de Köhler con chimpancés "no solo en los famosos estudios de Köhler sobre los chimpancés, sino en otras muchas provincias de la psicología animal aparece, más o menos problemáticamente, la capacidad del animal de producir instrumentos elementales"70, sin que les podamos atribuir capacidad para imaginar diferentes programas de ser; $y$, por otro lado, Ortega afirma reiteradamente que no basta con tener una capacidad para ejercitarla. Niega Ortega que "la presencia de una capacidad explique, sin más, su ejercicio y actualización"71. La inteligencia técnica es una capacidad, pero la técnica es la ejecución efectiva de dicha capacidad, que se puede o no llegar a realizar.

En referencia a la imaginación: "Antes de la inteligencia y como motor de ésta, Ortega sitúa la imaginación, la facultad de inventar, la capacidad para crear proyectos no reiterados mecánicamente"72.

Por eso, la inteligencia, aun para el ejercicio que es la técnica, necesita de la imaginación y la presupone. La imaginación entendida como la capacidad para crear proyectos vitales; una capacidad, por tanto, profundamente humana, pues no sólo tiene la característica de sobrepasar lo ya dado, es decir, de hacer vida propiamente humana, que es siempre creadora, sino que, sobre todo, está en la raíz misma de la vida humana, en cuanto es la decisiva creadora del proyecto vital, en función del cual se pone en movimiento todo lo que es vida humana. [...]. La imaginación es, al contrario, la facultad de lo radicalmente nuevo y renovador, el punto de base donde psíquicamente se diferencia la existencia humana de la animal ${ }^{73}$.

La segunda manifestación donde se concretiza el ser de la técnica es en su evolución: "al no ser el hombre una dimensión fija y el ser de la técnica una función del programa vital que el hombre ha ido siendo, tan distinto a lo largo de la historia"74. La causa de la existencia de diferentes técnicas hay que buscarla en los programas vitales que han prevalecido en las distintas sociedades. No puede darse la misma técnica en una sociedad donde la figura de vida es la del gentleman que en una sociedad donde el programa de ser sea el del bodhisatva

\footnotetext{
70 "Ensimismamiento y alteración": V, 587.

${ }^{71}$ Ignacio Ellacuría, "Técnica y vida humana en Ortega y Gasset. Estudio de "Meditación de la técnica", ob. cit., p. 509

72 Ibíd., p. 510.

${ }^{73}$ Ibíd., p. 510

${ }^{74}$ Ibíd., p. 511
} 
hindú. De ahí que los historiadores han distinguido entre diferentes etapas técnicas. Ortega entre las diferentes opciones para segmentar las diferentes etapas técnicas cree que no es la existencia de un invento u otro, por muy relevante que hayan sido, lo que determina la evolución técnica. Para Ortega los actos técnicos están en función de la idea de vida que el hombre en cada etapa histórica ha ido teniendo, esto es, la idea que en cada época ha tenido de "bienestar". Los inventos solo "adquieren significación al ponerlos en función de un programa vital, y no logran su eficiencia histórica sino al integrarse en el programa vital de un tiempo determinado"75.

Ortega distingue tres grandes estadios en la evolución de la técnica: la técnica del azar, la técnica del artesano y la técnica del técnico. La técnica del azar se caracteriza porque el primitivo no diferencia entre los actos naturales y los actos técnicos, como consecuencia de ello ignora su propia capacidad técnica. Los hallazgos casuales parecen tener algo de mágicos. En cambio, en el segundo estadio de la técnica, la técnica del artesano, la figura del artesano es central. Se diferencia de la técnica del azar en que la técnica ha crecido en cantidad y en complejidad. Considera Ortega que todavía no hay conciencia de la técnica como función genérica, sino que la técnica está unida al hombre que la utiliza, no hay técnica sino técnicos. En último lugar, la técnica del técnico se caracteriza por un desarrollo técnico exponencial. El ser humano tiene conciencia de su capacidad para realizar actos y productos técnicos. La técnica se le aparece al hombre como capacidad en principio ilimitada.

Queda así definitivamente caracterizada la técnica. Ortega ha visto bien que si la técnica es un fenómeno que se da dondequiera aparece la vida humana, ésta tiene que decir relación esencial a la técnica y viceversa; investigando en lo que es la vida humana y en la raíz que se descubre en los actos técnicos, determina cuál es esa relación esencial: la posibilitación permanente de una vida propiamente humana por medio de la transformación de la naturaleza y la creación de una sobrenaturaleza. ${ }^{76}$

\section{CONCLUSIONES}

Ellacuría nos muestra en los diferentes artículos y ensayos que escribió sobre Ortega un intento de comprender a Ortega desde dentro, apreciando sus valores

\footnotetext{
75 Ibíd., p. 511

76 Ibíd., pp. 517-518
} 
positivos y sus posibles deficiencias, analizando sus textos de una manera mesurada y serena. En segundo lugar, hay que resaltar el estudio que realizó sobre el libro Meditación de la técnica. Por una parte, por ser pionero en el estudio de la filosofía de la técnica de Ortega, pues hasta ese momento sólo se habían escrito algunos artículos pero nada parecido al ensayo de Ellacuría por la extensión del texto, por la profundidad y minuciosidad con que estudia la filosofía de la técnica orteguiana, $y$, por otra parte, al señalar como punto más importante del texto Meditación de la técnica la radicación por parte de Ortega de la técnica en la vida humana, dato radical y eje donde pivota todo el sistema orteguiano. Por último, de la crítica que realizó Ellacuría al libro de Santiago Ramírez podemos inferir que las posiciones de rechazo y valoraciones negativas de la Iglesia católica respecto de la filosofía y figura de Ortega y Gasset no eran tan monolíticas como se ha transmitido, ya que las diferencias de opinión de Ellacuría y Ramírez quedan patentes.

\section{REFERENCIAS BIBLIOGRÁFICAS}

Aranguren, J. L. (1958), La ética de Ortega. Madrid: Cuadernos Taurus, (2ºd) ElLACURÍA, I. (1996), "Ortega y Gasset, hombre de nuestro ayer", en Escritos filosóficos I. San Salvador: UCA Editores, pp. 15-22.

-, (1996), "Ortega y Gasset, desde dentro", en Escritos filosóficos I, San Salvador: UCA Editores pp. 23-33.

-, (1996), "¿Quién es Ortega y Gasset?, en Escritos filosóficos I. San Salvador: UCA Editores, pp.34-35.

- (1996), "Correspondencia con Ángel Martínez", en Escritos filosóficos I, San Salvador: UCA Editores pp. 198-213.

—, (1996), "Posibilidad y modo de aproximación entre la filosofía escolástica y la filosofía moderna (Reflexiones ante el libro de Ramírez: La filosofía de Ortega y Gasset), en Escritos filosóficos I. San Salvador: UCA Editores, pp. 223-250.

-, "Ortega, existencia desligada", en Escritos filosóficos I. San Salvador: UCA Editores, pp. 265-270. 
- "Técnica y vida humana en Ortega y Gasset. Estudio de "Meditación de la técnica", en Escritos filosóficos I. San Salvador: UCA Editores, pp. 415518.

FRAILE, G. (1958), "El P. Ramírez escribe sobre Ortega", Salmanticensis, n5, pp. 231-239.

IRIARTE, J (1942), Ortega y Gasset. Su persona y su doctrina. Madrid: Razón y Fe Laín Entralgo, P. (1958), "Los católicos y Ortega", Cuadernos Hispano Americanos, n०101, pp. 329-352.

LASAGA, J. (2003), José Ortega y Gasset. (1883-1955). Vida y filosofía. Madrid: Biblioteca Nueva.

MARAÑón, G. (1955), "Universidad y retórica en Ortega", $A B C, 20$ de octubre de 1955.

ORTEGA Y GASSET, J. (2004-2010), Obras completas. Madrid: Taurus/Fundación José Ortega y Gasset.

PARÍs, C. (1956), "Meditación sobre la filosofía de Ortega", Arbor, 33 (123), pp. 329-352.

RAMíREZ, S. (1958), La filosofía de Ortega y Gasset. Barcelona: Herder.

SAn MARTín, J. (1998), Fenomenología y cultura en Ortega. Madrid: Tecnos.

- (2012), La fenomenología de Ortega. Madrid: Biblioteca Nueva. 